\title{
A Method to Predict Infinity Values for Biexponential Processes
}

\author{
J. Newburger, ${ }^{1}$ John G. Wagner, ${ }^{2}$ and S. Stavchansky ${ }^{1}$ \\ Received July 24, 1978-Final February 16, 1979
}

An equation is presented which allows infinity values for biexponential processes to be predicted in the early nonlinear phase when samples are taken at equal time intervals. This equation is independent of the value or ratio of the rate constants involved in the process. However, this method is very sensitive to noise normally associated with urine data.

KEY WORDS: biexponential; equal time intervals; infinity values.

\section{INTRODUCTION}

One of the methods used to assess bioavailability is to determine the total amount of drug and/or metabolite(s) (infinity values) appearing in the urine. Guggenheim (1) and Amidon et al. (2) have both proposed different forms of the same equation to predict these infinity values for monoexponential processes, where sample are taken at equal time intervals. The equation may be written in the general form of

$$
Y_{\infty}=Y_{i+2}-\left(Y_{i+2}-Y_{i+1}\right)^{2} /\left(Y_{i+2}-2 Y_{i+1}+Y_{i}\right)
$$

where $Y_{\infty}$ is the terminal value of $Y$ and $Y_{i}, Y_{i+1}$, and $Y_{i+2}$ are sucessive values of $Y$ taken at equal time intervals during the time course of the study.

Wagner and Ayres (3) have written equation 1 as

$$
Y_{i}=Y_{\infty}-\text { slope }\left(Y_{i+1}-Y_{i}\right)
$$

which can be used to plot the data allowing more than three observations to be used in the determination of $Y_{\infty}$. The slope of equation 2 can be shown to

\footnotetext{
${ }^{1}$ Drug Dynamics Institute, College of Pharmacy, The University of Texas at Austin, Austin, Texas 78712 .

${ }^{2}$ College of Pharmacy and Upjohn Center for Clinical Pharmacology, The University of Michigan Medical Center, Ann Arbor, Michigan 48109.
} 
be equal to $-1 /\left(1-e^{-k \Delta t}\right)$; therefore,

$$
Y_{i}=Y_{\infty}-\left[1 /\left(1-e^{-k \Delta t}\right)\right]\left[Y_{i+1}-Y_{i}\right]
$$

which allows $Y_{\infty}$ to be determined from the intercept of the graph and the rate constant $k$ to be evaluated from the slope of the line, where $\Delta t$ is the equal time interval at which samples are taken. Wagner (4) has shown that the Guggenheim equation corresponding to equation 3 may be written as

$$
\left.\ln \left(Y_{i+1}-Y_{i}\right)=\ln Y_{\infty}\left(1-e^{-k \Delta t}\right)\right]-k t_{i}
$$

However, equation 4 will make terrible estimates of the infinity value and rate constant $k$ from data at equal time intervals, whereas equation 3 with either ordinary or orthogonal least squares will make excellent estimates (5).

These equations can be used in biexponential processes provided that they are applied during the terminal linear phase of the biexponential process. This could require collection of urine samples over relatively long time periods to assure being in the linear phase. The purpose of this communication is to propose an equation which will allow prediction of the infinity values for the biexponential processes during the nonlinear phase. This equation is independent of the rate constants and may be used during the early period of the study, provided that samples are taken at equal time intervals.

This technique is described in Hildebrand (6) as Prony's method of exponential approximation. It is an exact solution (non-least-squares) and can be very sensitive to noise normally associated with urine data and may produce large errors especially if there is much deviation of the data from the exact line. Included in the discussion is an example of the error which may result from rounding off the data as discussed by Hildebrand (6).

\section{THEORETICAL AND DISCUSSION}

Juhl et al. (7) have investigated the effect of sulfasalazine on digoxin bioavailability by measuring urinary digoxin excretion. Wagner and Ayres (3) have applied various methods to these data to estimate the total amount of digoxin appearing in the urine. All of the methods used by Wagner and Ayres (3) assume that the data become linear at 3 days, and the data from this point on were fitted to various monoexponential functions. If the following equation is used (see Appendix for derivation),

$$
\begin{aligned}
Y_{\infty}=\frac{2 Y_{2} Y_{3} Y_{4}+}{Y_{1} Y_{5} Y_{3} Y_{5}-Y_{1} Y_{4}^{2}-Y_{5} Y_{2}^{2}-Y_{3}^{3}-2 Y_{1} Y_{4}-2 Y_{2} Y_{5}+2 Y_{2} Y_{4}} \\
+2 Y_{2} Y_{3}+Y_{3} Y_{5}+2 Y_{3} Y_{4}-Y_{2}^{2}-3 Y_{3}^{2}-Y_{4}^{2}
\end{aligned}
$$


Table I

\begin{tabular}{|c|c|c|c|}
\hline Method & $\begin{array}{l}\text { Number of } \\
\text { data points }\end{array}$ & $\begin{array}{l}\text { Digoxin alone } \\
\qquad(\mu \mathrm{g})\end{array}$ & $\begin{array}{c}\text { Digoxin + } \\
\text { sulfasalazine } \\
\quad(\mu \mathrm{g})\end{array}$ \\
\hline \multicolumn{4}{|l|}{ Juhl et al. (7) } \\
\hline $\begin{array}{l}(2,4,8,12,24 \mathrm{hr}, 2,3,4,5,6,7,8,9,10 \\
{\text { days })^{a}}^{a}\end{array}$ & 14 & 278 & 228 \\
\hline \multicolumn{4}{|l|}{ Equation 5} \\
\hline$(1,2,3,4$, and 5 days $)$ & 5 & 276 & 231 \\
\hline$(0.5,1,1.5,2$, and 2.5 days $)$ & 5 & 281 & 233 \\
\hline \multicolumn{4}{|l|}{ Wagner and Ayres (3) } \\
\hline Method $\mathrm{I}(3,4,5,6,7,8,9$, and 10 days $)$ & 8 & 285 & 234 \\
\hline Method IIA $(3,4$, and 5 days $)$ & 3 & 303 & 229 \\
\hline Method IIB ( $3,4,5$, and 6 days) & 4 & 281 & 224 \\
\hline $\begin{array}{l}\text { Method IIB }(3,4,5,6,7,8,9 \text {, and } 10 \\
\text { days) }\end{array}$ & 8 & 284 & 232 \\
\hline Method $\operatorname{IIC}(3,4,5$, and 6 days $)$ & 4 & 282 & 232 \\
\hline $\begin{array}{l}\text { Method } \operatorname{IIC}(3,4,5,6,7,8,9 \text {, and } 10 \\
\text { days) }\end{array}$ & 8 & 285 & 234 \\
\hline
\end{tabular}

${ }^{a}$ Numbers in parentheses indicate the time at the end of each collection.

data points in the nonlinear phase of the process may be used, and the problem of determining when linearity begins is avoided. Also, equation 5 may be used during the early time periods, reducing the number of samples needed in the study. Table I shows the results obtained by Juhl $e$ t al. (7), by Wagner and Ayres (3), and by using equation 5. Two sets of data are presented for equation 5. One set uses the data points extrapolated for the first 5 days by Wagner and Ayres (3). The other set is a combination of the $0.5,1$-, and 2-day points extrapolated by Wagner and Ayres (3) and the 1.5and 2.5-day points extrapolated by the authors. The data points at 1.5 and 2.5 days for digoxin alone are 143 and $186 \mu \mathrm{g}$, respectively, and 118 and $152.5 \mu \mathrm{g}$, respectively, for digoxin in the presence of sulfasalazine. The results obtained by using equation 5 compare favorably with those reported by both Juhl et al. (7) and Wagner and Ayres (3). The advantage of equation 5 lies in the fact that results may be obtained in 2.5 days, which is the early nonlinear portion of the curve.

The following two examples are presented to illustrate the situation where the data show no linearity; thus it would be inappropriate to use the methods of Wagner and Ayres (3). Cabana et al. (8) administered a 950-mg i.v. dose of Cephapirin to human volunteers and collected nine equally spaced urine samples over a period of $6.04 \mathrm{hr}$. Using a two-compartment open model analysis, Cabana et al. (8) reported that a total of $455 \mathrm{mg}$ of Cephapirin and $317 \mathrm{mg}$ of the metabolite appear in the urine. Using the first five data points in equation 5, over a time period of $2.54 \mathrm{hr}$, values of $449 \mathrm{mg}$ of intact drug $(1.3 \%$ difference $)$ and $315 \mathrm{mg}$ of metabolite $(0.63 \%$ 
Table II. Oxacillin, $250 \mathrm{mg}$ i.v. bolus; Sulfaethidole, $1.0 \mathrm{~g} \mathrm{oral}^{a}$

\begin{tabular}{crrrrrr}
\hline \multicolumn{7}{c}{ Cumulative amount of oxacillin in urine (mg) } \\
\hline Time (hr) & B. R. & B. M. & E. S. & L. D. & D. K. & Mean \pm SD \\
\hline 0.5 & 92.0 & 90.0 & 75.6 & 90.1 & 91.0 & $87.7 \pm 6.83$ \\
1.0 & 103.2 & 108.4 & 88.8 & 106.0 & 113.0 & $103.9 \pm 9.2$ \\
1.5 & 108.1 & 112.9 & 92.9 & 109.9 & 119.5 & $108.7 \pm 9.8$ \\
2.0 & 110.0 & 114.8 & 94.9 & 112.2 & 122.1 & $110.8 \pm 10.0$ \\
2.5 & 111.6 & 116.7 & 95.8 & 113.0 & 123.5 & $112.1 \pm 10.2$ \\
3.0 & - & - & 96.5 & 113.7 & 124.7 & $113.0 \pm 10.4$ \\
3.5 & 12.9 & 117.6 & 96.9 & 114.2 & 125.6 & $113.4 \pm 10.5$ \\
4.0 & 113.1 & 118.0 & 97.3 & 114.6 & 126.3 & $113.9 \pm 10.6$ \\
\hline
\end{tabular}

${ }^{a}$ Data taken from the Ph.D. dissertation submitted by Karl A. DeSante in partial fulfillment for the requirements for the Doctor of Philosophy Degree at The University of Kentucky (1972). Reproduced with permission of the author (9).

difference) were predicted to appear in the urine. Table II presents the data of DeSante (9), who gave a $250-\mathrm{mg}$ i.v. dose of oxacillin along with a $1.0-\mathrm{g}$ oral dose of sulfaethidole to human volunteers. Using eight data points and two-compartment open model analysis, he reported a total of $113.9 \mathrm{mg}$ of oxacillin appearing in the urine. Applying equation 5 to the first five data points, a predicted value of $116.5 \mathrm{mg}$ ( $2.3 \%$ difference) was obtained.

The following data, shown in Tables III and IV, were simulated to illustrate the sensitivity of the method as described by Hildebrand (6). Using the solution for the one-compartment open model

$$
Y_{\infty}=\left(Y_{2}^{2}-Y_{1} Y_{3}\right) /\left(2 Y_{2}-Y_{1}-Y_{3}\right)
$$

for data given to three decimal places (Table III) gives a result of $100.1 \mathrm{mg}$ for $Y_{\infty}(0.1 \%$ error $)$. Using the data given to two decimal places gives a result of $98.49 \mathrm{mg}$ for $Y_{\infty}(1.51 \%$ error $)$.

Using the solution of the two-compartment model, previously shown as equation 5 , for the data given to three decimal places in Table IV gives a result of $99.96 \mathrm{mg}(0.04 \%$ error $)$. Using the data given to two decimal places gives a result of $108.98 \mathrm{mg}(8.98 \%$ error $)$.

Table III. Simulated Data for the One-Compartment Open Model $\left(k_{u}=0.05 / \mathrm{hr}, \text { dose }=100 \mathrm{mg}\right)^{a}$

\begin{tabular}{|c|c|c|}
\hline $\begin{array}{l}\text { Time } \\
\text { (hr) }\end{array}$ & $Y_{2} \underset{(\mathrm{mg})}{\text { cumulative }}$ & $\underset{(\mathrm{mg})}{Y_{t} \text { cumulative }}$ \\
\hline 1.0 & 4.877 & 4.88 \\
\hline 2.0 & 9.516 & 9.52 \\
\hline 3.0 & 13.929 & 13.93 \\
\hline
\end{tabular}


Table IV. Simulated Data for the Two-Compartment Open Model Bolus Injection $(\alpha=1.0 / \mathrm{hr}, \beta=0.05 / \mathrm{hr}, A=10.0 \mathrm{mg}, B=90.0 \mathrm{mg}$, dose $=100 \mathrm{mg})^{a}$

\begin{tabular}{ccc}
\hline $\begin{array}{c}\text { Time } \\
(\mathrm{hr})\end{array}$ & $\begin{array}{c}Y_{t} \text { cumulative } \\
(\mathrm{mg})\end{array}$ & $\begin{array}{c}Y_{i} \text { cumulative } \\
(\mathrm{mg})\end{array}$ \\
\hline 1.0 & 10.711 & 10.71 \\
2.0 & 17.211 & 17.21 \\
3.0 & 22.038 & 22.04 \\
4.0 & 26.131 & 26.13 \\
5.0 & 29.841 & 29.84 \\
\hline${ }^{a} Y_{\infty}-Y_{t}=A e^{-\alpha t}+B e^{-\beta t}$. &
\end{tabular}

\section{CONCLUSIONS}

An equation has been presented which allows prediction of infinity values for both intact drug and metabolite appearing in the urine for exponential processes, provided that samples are taken at equal time intervals. This method allows data to be used in the early nonlinear place of the biexponential process. However, this technique must be used with caution as it is very sensitive to noise which is usually associated with urine data and may result in large errors.

\section{APPENDIX}

The general equation for the biexponential process may be written as

$$
Y_{\infty}-Y_{t}=A e^{-k^{\prime} t}+B e^{-k^{\prime \prime} t}
$$

1. Oral absorption model (single dose):

$$
\begin{gathered}
D_{G} \longrightarrow D_{B} \stackrel{k_{a}}{\text { (drug in gut) }} \longrightarrow \quad D_{U} \\
Y_{\infty}-Y_{\mathrm{t}}=\frac{k_{a} D_{0} f}{k_{a}-k_{\mathrm{el}}} e^{-k_{\mathrm{e} 1} t}+\frac{k_{\mathrm{el}} D_{0} f}{k_{\mathrm{el}}-k_{a}} e^{-k_{a} t}
\end{gathered}
$$

2. Intavenous model (single bolus dose):

$$
\begin{gathered}
D_{U} \stackrel{k_{\mathrm{ei}}}{\longleftarrow} D_{B} \rightleftharpoons \frac{k_{1}}{\text { (drug in urine) } \quad\left(\begin{array}{c}
\text { drug in central } \\
\text { compartment }
\end{array}\right)} D_{T}^{k_{2}}\left(\begin{array}{c}
\text { drug in peripheral } \\
\text { compartment }
\end{array}\right) \\
Y_{\infty}-Y_{t}=\frac{k_{\mathrm{el}} D_{0}\left(k_{2}-\alpha\right)}{(\beta-\alpha)(\alpha)} e^{-\alpha t}+\frac{k_{\mathrm{el}} D_{0}\left(k_{2}-\beta\right)}{(\alpha-\beta)(\beta)} e^{-\beta t}
\end{gathered}
$$


$Y_{\infty}=$ total amount of drug appearing in the urine.

$Y_{t}=$ cumulative amount of drug appearing in the urine at time $t$.

$t=$ time of urine collection.

$D_{0}=$ dose.

$f=$ fraction of dose absorbed.

$k_{a}=$ absorption rate constant

$k_{\mathrm{el}}=$ rate constant for transfer of drug from central compartment to urine.

$k_{1}=$ rate constant for transfer of drug from central compartment to peripheral compartment.

$k_{2}=$ rate constant for transfer of drug from peripheral compartment to central compartment.

$\alpha$ and $\beta=$ complicated constants composed of the system of microparameters.

Using the method of equal time intervals suggested by Guggenheim (1), such that $t_{i}=i \Delta t ; i=1,2,3 \ldots$, then the following equations may be written:

$$
\begin{aligned}
& Y_{\infty}-Y_{1}=A e^{-k_{1} \Delta t}+B e^{-k_{2} \Delta t} \\
& Y_{\infty}-Y_{2}=A e^{-2 k_{1} \Delta t}+B e^{-2 k_{2} \Delta t} \\
& Y_{\infty}-Y_{3}=A e^{-3 k_{1} \Delta t}+B e^{-3 k_{2} \Delta t} \\
& Y_{\infty}-Y_{4}=A e^{-4 k_{1} \Delta t}+B e^{-4 k_{2} \Delta t} \\
& Y_{\infty}-Y_{5}=A e^{-5 k_{1} \Delta t}+B e^{-5 k_{2} \Delta t}
\end{aligned}
$$

If equations $4 a, 5 a$, and $6 a$ are written as

$$
\begin{aligned}
& Y_{\infty}-Y_{1}=A e^{-k_{1} \Delta t}(1)+B e^{-k_{2} \Delta t}(1) \\
& Y_{\infty}-Y_{2}=A e^{-k_{1} \Delta t}\left(e^{-k_{1} \Delta t}\right)+B e^{-k_{2} \Delta t}\left(e^{-k_{2} \Delta t}\right) \\
& Y_{\infty}-Y_{3}=A e^{-k_{1} \Delta t}\left(e^{-2 k_{1} \Delta t}\right)+B e^{-k_{2} \Delta t}\left(e^{-2 k_{2} \Delta t}\right)
\end{aligned}
$$

then the following determinants and equalities may be written:

\section{A}

$$
\begin{gathered}
\left|\begin{array}{ccc}
\left(Y_{\infty}-Y_{1}\right) & (1) & (1) \\
\left(Y_{\infty}-Y_{2}\right) & \left(e^{-k_{1} \Delta t}\right) & \left(e^{-k_{2} \Delta t}\right) \\
\left(Y_{\infty}-Y_{3}\right) & \left(e^{-2 k_{1} \Delta t}\right) & \left(e^{-2 k_{2} \Delta t}\right)
\end{array}\right|= \\
B \\
\left|\begin{array}{ccc}
\left(Y_{\infty}-Y_{1}-A e^{-k_{1} \Delta t}-B e^{-k_{2} \Delta t}\right) & (1) & (1) \\
\left(Y_{\infty}-Y_{2}-A e^{-2 k_{1} \Delta t}-B e^{-2 k_{2} \Delta t}\right) & \left(e^{-k_{1} \Delta t}\right) & \left(e^{-k_{2} \Delta t}\right. \\
\left(Y_{\infty}-Y_{3}-A e^{-3 k_{1} \Delta t}-B e^{-3 k_{2} \Delta t}\right) & \left(e^{-2 k_{1} \Delta t}\right) & \left(e^{-2 k_{2} \Delta t}\right)
\end{array}\right|=
\end{gathered}
$$


C

$$
\left|\begin{array}{ccc}
0 & (1) & (1) \\
0 & \left(e^{-k_{1} \Delta t}\right) & \left(e^{-k_{1} \Delta t}\right) \\
0 & \left(e^{-2 k_{1} \Delta t}\right) & \left(e^{-2 k_{2} \Delta t}\right)
\end{array}\right|=0
$$

Repeating this procedure for equations $5 \mathrm{a}, 6 \mathrm{a}$, and $7 \mathrm{a}$ and again for equations $6 \mathrm{a}, 7 \mathrm{a}$, and $8 \mathrm{a}$ allows the following determinants to be written and shows that all the resulting determinants are equal:

$$
\begin{aligned}
& \left|\begin{array}{ccc}
\left(Y_{\infty}-Y_{1}\right) & (1) & (1) \\
\left(Y_{\infty}-Y_{2}\right) & \left(e^{-k_{1} \Delta t}\right) & \left(e^{-k_{2} \Delta t}\right) \\
\left(Y_{\infty}-Y_{3}\right) & \left(e^{-2 k_{1} \Delta t}\right) & \left(e^{-2 k_{1} \Delta t}\right)
\end{array}\right|= \\
& \left|\begin{array}{ccc}
\left(Y_{\infty}-Y_{2}\right) & (1) & (1) \\
\left(Y_{\infty}-Y_{3}\right) & \left(e^{-k_{1} \Delta t}\right) & \left(e^{-k_{2} \Delta t}\right) \\
\left(Y_{\infty}-Y_{4}\right) & \left(e^{-2 k_{1} \Delta t}\right) & \left(e^{-2 k_{2} \Delta t}\right)
\end{array}\right|= \\
& \left|\begin{array}{ccc}
\left(Y_{\infty}-Y_{3}\right) & (1) & (1) \\
\left(Y_{\infty}-Y_{4}\right) & \left(e^{-k_{1} \Delta t}\right) & \left(e^{-k_{2} \Delta t}\right. \\
\left(Y_{\infty}-Y_{5}\right) & \left(e^{-2 k_{1} \Delta t}\right) & \left(e^{-2 k_{2} \Delta t}\right)
\end{array}\right|
\end{aligned}
$$

The solution for determinant $D$ can be obtained by letting $x=e^{-k_{1} \Delta t}$, $x^{2}=e^{-2 k_{1} \Delta t}, y=e^{-k_{2} \Delta t}$, and $y^{2}={ }^{-2 k_{2} \Delta t}$. Thus

$$
\begin{aligned}
\left(Y_{\infty}-Y_{1}\right)\left(x y^{2}-y x^{2}\right)-\left(Y_{\infty}-Y_{2}\right)\left(y^{2}-x^{2}\right)+\left(Y_{\infty}-Y_{3}\right)(y-x) & =0 \\
\left(Y_{\infty}-Y_{1}\right)(x y)(y-x)-\left(Y_{\infty}-Y_{2}\right)(y-x)(y+x)+\left(Y_{\infty}-Y_{3}\right)(y-x) & =0 \\
\left(Y_{\infty}-Y_{1}\right)(x y)-\left(Y_{\infty}-Y_{2}\right)(y+x)+\left(Y_{\infty}-Y_{3}\right) & =0
\end{aligned}
$$

Similar solutions obtained for determinants $E$ and $F$ lead to

$$
\begin{aligned}
& \left(Y_{\infty}-Y_{2}\right)(x y)-\left(Y_{\infty}-Y_{3}\right)(y+x)+\left(Y_{\infty}-Y_{4}\right)=0 \\
& \left(Y_{\infty}-Y_{3}\right)(x y)-\left(Y_{\infty}-Y_{4}\right)(y+x)+\left(Y_{\infty}-Y_{5}\right)=0
\end{aligned}
$$

The solutions of determinants $D, E$, and $F$ (equations 14a, 15a, and 16a) allow the development of the following determinants:

$$
\begin{aligned}
& \text { G } H \\
& \left|\begin{array}{lll}
\left(Y_{\infty}-Y_{1}\right) & \left(Y_{\infty}-Y_{2}\right) & \left(Y_{\infty}-Y_{3}\right) \\
\left(Y_{\infty}-Y_{2}\right) & \left(Y_{\infty}-Y_{3}\right) & \left(Y_{\infty}-Y_{4}\right) \\
\left(Y_{\infty}-Y_{3}\right) & \left(Y_{\infty}-Y_{4}\right) & \left(Y_{\infty}-Y_{5}\right)
\end{array}\right|=\left|\begin{array}{lll}
\left(Y_{\infty}-Y_{1}\right) & \left(Y_{1}-Y_{2}\right) & \left(Y_{2}-Y_{3}\right) \\
\left(Y_{\infty}-Y_{2}\right) & \left(Y_{2}-Y_{3}\right) & \left(Y_{3}-Y_{4}\right) \\
\left(Y_{\infty}-Y_{3}\right) & \left(Y_{3}-Y_{4}\right) & \left(Y_{4}-Y_{5}\right)
\end{array}\right|
\end{aligned}
$$


which can be written as

$$
\left|\begin{array}{ccc}
I \\
Y_{\infty} & \left(Y_{1}-Y_{2}\right) & \left(Y_{2}-Y_{3}\right) \\
Y_{\infty} & \left(Y_{2}-Y_{3}\right) & \left(Y_{3}-Y_{4}\right) \\
Y_{\infty} & \left(Y_{3}-Y_{4}\right) & \left(Y_{4}-Y_{5}\right)
\end{array}\right|-\left|\begin{array}{lll}
Y_{1} & \left(Y_{1}-Y_{2}\right) & \left(Y_{2}-Y_{3}\right) \\
Y_{2} & \left(Y_{2}-Y_{3}\right) & \left(Y_{3}-Y_{4}\right) \\
Y_{3} & \left(Y_{3}-Y_{4}\right) & \left(Y_{4}-Y_{5}\right)
\end{array}\right|
$$

or

$$
Y_{\infty}=\left|\begin{array}{lll}
1 & \left(Y_{1}-Y_{2}\right) & \left(Y_{2}-Y_{3}\right) \\
1 & \left(Y_{2}-Y_{3}\right) & \left(Y_{3}-Y_{4}\right) \\
1 & \left(Y_{3}-Y_{4}\right) & \left(Y_{4}-Y_{5}\right)
\end{array}\right|-\left|\begin{array}{ccc}
Y_{1} & \left(Y_{1}-Y_{2}\right) & \left(Y_{2}-Y_{3}\right) \\
Y_{2} & \left(Y_{2}-Y_{3}\right) & \left(Y_{3}-Y_{4}\right) \\
Y_{3} & \left(Y_{3}-Y_{4}\right) & \left(Y_{4}-Y_{5}\right)
\end{array}\right|
$$

or

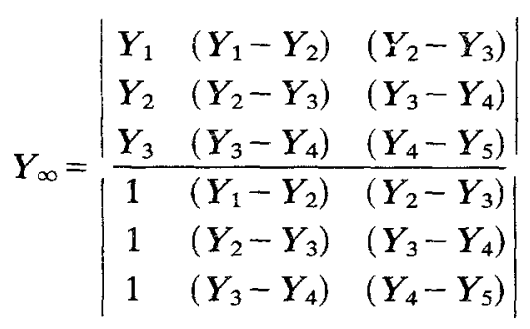

which leads to the following solution for $Y_{\infty}$ :

$$
\begin{aligned}
Y_{\infty}=\frac{2 Y_{2} Y_{3} Y_{4}}{}+Y_{1} Y_{3} Y_{5}-Y_{2} Y_{4}^{2}-Y_{5} Y_{2}^{2}-Y_{3}^{3} \\
Y_{1} Y_{5}+Y_{1} Y_{3}-2 Y_{1} Y_{4}-2 Y_{2} Y_{5}+2 Y_{2} Y_{4} \\
+2 Y_{2} Y_{3}+Y_{3} Y_{5}-2 Y_{3} Y_{4}-Y_{2}^{2}-3 Y_{3}^{2}-Y_{4}^{2}
\end{aligned}
$$

\section{ACKNOWLEDGMENT}

The authors wish to express their appreciation to Dr. Don E. Edmonson for his help with the manuscript.

\section{REFERENCES}

1. E. A. Guggenheim. On the determination of the velocity constant of a unimolecular reaction. Phil. Mag. 2:538-543 (1926).

2. G. L. Amidon, M. J. Paul, and P. G. Welling. Model-independent prediction methods in pharmacokinetics: Theoretical considerations. Math. Biosci. 25:259-272 (1975). 
3. J. G. Wagner and J. W. Ayres. Bioavailability assessment: Models to estimate total area (AUC $0-\infty)$ and total amount excreted $\left(A_{e}^{\infty}\right)$ and importance of blood and urine sampling scheme with application to digoxin. J. Pharmacokin. Biopharm. 5:533-557 (1977).

4. J. G. Wagner. Findamentals of Clinical Pharmacokinetics, Drug Intelligence Publications, Hamilton, Ill., 1975, p. 184.

5. J. G. Wagner, personal communication.

6. F. B. Hildebrand. Introduction to Numerical Analysis, McGraw-Hill, New York, 1975, pp. 378-381.

7. R. P. Juhl, R. W. Summers, J. K. Guillory, S. M. Baugh, F. H. Cheng, and D. B. Brown. Effects of sulfasalazine on digoxin bioavailability. Clin. Pharmacol. Ther. 20:387-394 (1976).

8. B. E. Cabana, D. R. VanHarken, G. H. Hottendorf, J. T. Doluisio, W. D. Griffin, Jr., D. W. A. Bourne, and L. W. Dittert. The role of the kidney in the elimination of cephapirin in man. J. Pharmacokin. Biopharm. 3:419-438 (1975).

9. K. A. DeSante. The influence of a highly protein bound sulfonamide on the human pharmacokinetics of various pericillins. A dissertation submitted in partial fulfillment of the requirements for the degree of Doctor of Philosophy, University of Kentucky, 1972. 